\title{
Mathematical Modelling \& Pressure Drop Analysis of Fused Deposition Modelling Feed Wire
}

\author{
Abid Haleem ${ }^{1}$, Vineet Kumar $^{2}$, Lalit Kumar ${ }^{3}$ \\ 1,2,3 Department of Mechanical Engineering \\ Faculty of Engineering and Technology, Jamia Millia Islamia, New Delhi 110025, INDIA \\ ${ }^{1}$ Email: haleem.abid@gmail.com, ahaleem@jmi.ac.in, Tel: +91-9818501633 \\ ${ }^{2}$ Email: mnnitrana@gmail.com, Tel: +91-9350478104 \\ ${ }^{3}$ Email: Rathee.lalit.2007@gmail.com, Tel: +91-9466096345
}

Abstract - Fused deposition modelling machine is an environment friendly additive manufacturing technology which is free from geometry of part to be print. In this technology Poly lactic acid (PLA) a biodegradable feed wire is used as a raw material to print the part. In this paper a mathematical model of feed wire is developed. Here in it the expression of total pressure drop is obtained by using Taylor's series expression including the temperature effect according to Arrhenius equation. The paper deals the effect of nozzle geometrical parameters like nozzle angle, exit diameter and section height on pressure drop and melts flow behavior of $3 \mathrm{~mm}$ PLA feed wire. The total pressure drop analysis is done by using the mathematical expression by varying nozzle angle from $30^{\circ}$ to $120^{\circ}$ and exit diameter from $0.2 \mathrm{~mm}$ to 0.4 mm.

Keywords- Additive Manufacturing, Modelling Feed Wire, Nozzle Geometrical Parameters, Nozzle Pressure Drop, Taylor's Series.

\section{INTRODUCTION}

Fused deposition modelling is categorized as an additive manufacturing technology which is based on the feed wire extrusion process through which part development takes place layer to layer deposition of raw material. The layer by layer deposition process repeated until the part completion takes place. The feed wire is feed by feeder mechanism in to isothermal nozzle which is maintained up to or above the glass transition temperature of the feed wire. The glass transition temperature of the feed wire is approximately $0.3 \mathrm{~T}_{\mathrm{m}}$ of (where $T_{m}$ is the melting point of feed wire) PLA feed wire. The feed wire is extruded at $200-220{ }^{0} \mathrm{C}$ from nozzle to get continuous discharge through exit of nozzle. The best possible exit diameter and nozzle angle parameter can be decided on the basis of pressure drop analysis for which a mathematical model of feed wire is developed. The feed wire element consider initially cylindrical in shape (as shown in Fig. 1) to get the expression of pressure drop. Now the Taylor series first order expression is used to find out the pressure drop including temperature effect by Arrhenius equation used in it. Now the study of feed wire at its melt flow condition is consider viscous laminar flow with Reynolds no $<5$. The study of feed wire is based on the following given assumptions.

a) Study state flow.

b) Flow is laminar $(\operatorname{Re}<5)$ means Inertia effect is dominate to viscous force.

c) Temperature of nozzle is constant over the whole nozzle (circular cross-section and tapered section).

d) Fully developed flow means velocity gradient is zero.

e) Incompressible flow.

f) Effect of gravity force is negligible.

g) There is no external force like magnetic etc.

h) Velocity near the wall surface is zero.

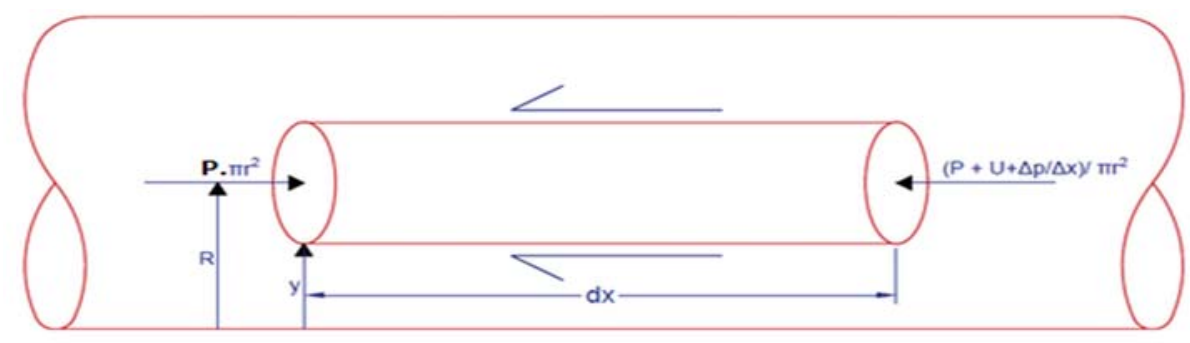

Fig. 1. Schematic diagram of viscous flow through nozzle 
Fig. 1 shows the cylindrical element of feed wire which is under consideration for the study, now according to equilibrium condition the pressure in terms of pressure force and shear stress (in terms of shear force) are represented according to Taylors series first order derivatives (discussed below).

\section{Mathematical Modelling of Feed WiRe}

The mathematical expression to find out the pressure drop for constant circular section 1 and section 2 is derived in this section and different symbols used for understanding mathematical equation are listed in TABLE 1 .

TABLE 1: Nomenclature of Symbols Used

\begin{tabular}{|l|l|}
\hline Symbol & Nomenclature \\
\hline $\mathrm{P}$ & Pressure \\
\hline $\mathrm{R}$ & Radius of filament \\
\hline $\mathrm{z}_{1}$ and $\mathrm{z}_{2}$ & Vertical height of nozzle section 1 and section 2 \\
\hline$\Theta$ & Nozzle tip angle \\
\hline$\emptyset_{\mathrm{f}}$ & Fluidity constant with respect to substance \\
\hline $\mathrm{M}$ & Melt flow index \\
\hline $\mathrm{v}_{\mathrm{i}}$ & Input velocity \\
\hline $\mathrm{Tw}$ & Working temperature \\
\hline $\mathrm{T}_{\text {abs }}$ & Absolute temperature in ${ }^{0} \mathrm{k}$ \\
\hline $\mathrm{T}_{\text {ref }}$ & Temperature at which $\varphi$ and $\mathrm{m}$ calculated \\
\hline $\mathrm{d}_{1}$ & Inlet diameter of nozzle \\
\hline $\mathrm{D}$ & Filament diameter \\
\hline $\mathrm{r}_{1}$ and $\mathrm{r}_{2}$ & $\mathrm{r}_{1}$ and $\mathrm{r}_{2}$ are the radius of nozzle \\
\hline$\mu$ & Viscosity of semi liquid substance \\
\hline $\mathrm{E}_{\mathrm{a}}$ & Activation energy \\
\hline$\Omega$ & Angular velocity \\
\hline$\tau_{\mathrm{r}}$ & Shear stress \\
\hline $\mathrm{Q}$ & Discharge of melt wire \\
\hline $\mathrm{u}_{\text {avg. }}$ & Average velocity of the fluid flow \\
\hline$\Delta \mathrm{P}_{1}$ & Pressure drop in section 1 \\
\hline$\Delta \mathrm{P}_{2}$ & Pressure drop in section 2 \\
\hline$\Delta \mathrm{P}_{\text {total }}$ & Total pressure drop across the nozzle \\
\hline
\end{tabular}

According to Taylor's series expression:

$$
p . \pi r^{2}-\left(p+\frac{\partial p}{\partial z} d z\right) \pi r^{2}-\tau .2 \pi r d z=0
$$

After solving this equation this produce

$$
\tau_{r}=-\frac{\partial p}{\partial z} \cdot \frac{r}{2}
$$

Now $\tau_{r}$ according to Ostwald power law equation and dynamic viscosity

$$
\mu=c\left(-\frac{\partial u}{\partial r}\right)^{m-1}
$$

Where $\mathrm{c}$ is the flow consistency index, $\frac{\partial u}{\partial r}$ is the shear strain rate and $\mathrm{m}$ is the non-dimension index.

$$
\begin{gathered}
\text { Let } \mathrm{m}=\frac{1}{n} \\
c=\phi_{f}^{-(1 / n)} \text { Then equation no (2) and (3) becomes }
\end{gathered}
$$




$$
\begin{gathered}
\mu=\phi_{f}^{-(1 / n)}\left(-\frac{\partial u}{\partial r}\right)^{(1 / n)-1} \\
\tau_{r}=\phi_{f}^{-(1 / n)}\left(-\frac{\partial u}{\partial r}\right)^{(1 / n)}
\end{gathered}
$$

Now using equation no (2) and (5)

$$
\begin{gathered}
\frac{\partial u}{\partial r}=-\phi_{f}\left[-\frac{\partial p}{\partial z} \frac{r}{2}\right]^{n} \\
\int \partial u=-\phi_{f}\left[-\frac{\partial p}{\partial z} \frac{1}{2}\right]^{n} \int r^{n} \partial r \\
u_{r}=-\phi_{f}\left[-\frac{\partial p}{\partial z} \frac{1}{2}\right]^{n} \frac{R^{n+1}}{n+1}+c \\
\text { Boundary condition } \\
c=\phi_{f}\left[-\frac{\partial p}{\partial z} \frac{1}{2}\right]^{n} \frac{R^{n+1}}{n+1}
\end{gathered}
$$

Now put value of c constant in equation no (8) from equation no (9)

$$
\begin{gathered}
u_{r}=\phi_{f}\left[-\frac{\partial p}{\partial z} \frac{1}{2}\right]^{n} \frac{1}{n+1}\left[R^{n+1}-r^{n+1}\right] \\
\text { Discharge quantity } \\
\int d q=\int 2 \pi r . d r u_{r}
\end{gathered}
$$

Put value of $u_{r}$ in equation no (11), which gives discharge after integration

$$
Q=\pi \phi_{f}\left[-\frac{\partial p}{\partial z} \frac{1}{2}\right]^{n} \frac{R^{n+3}}{n+3}
$$

$$
\text { Average velocity } \quad \bar{u}=\frac{\pi \phi_{f}\left[-\frac{\partial p}{\partial z} \frac{1}{2}\right]^{n} \frac{R^{n+3}}{n+3}}{\pi R^{2}}
$$

$$
\begin{aligned}
& \bar{u}=\phi_{f}\left[-\frac{\partial p}{\partial z} \frac{1}{2}\right]^{n} \frac{R^{n+1}}{n+3} \\
& {\left[-\frac{\partial p}{\partial z} \frac{1}{2}\right]^{n}=\frac{(n+3) \bar{u}}{R^{n+1} \phi_{f}}} \\
& {\left[-\frac{\partial p}{\partial z} \frac{1}{2}\right]=\left[\frac{(n+3) \bar{u}}{R^{n+1} \phi_{f}}\right]^{\frac{1}{n}}} \\
& \int \partial p=-2\left[\frac{(n+3) \bar{u}}{R^{n+1} \phi_{f}}\right]^{\frac{1}{n}} \int \partial z
\end{aligned}
$$


After integration the pressure drop is

$$
p_{2}-p_{1}=2\left[\frac{(n+3) \bar{u}}{R^{n+1} \phi_{f}}\right]^{\frac{1}{n}}\left(z_{1}-z_{2}\right)
$$

Now the viscosity is the function of temperature so according to Arrhenius Equations

$$
\begin{gathered}
H\left(T_{W}\right)=e^{\left[E_{A}\left(\frac{1}{T_{W}-T_{a b}}+\frac{1}{T_{a b}-T_{r f}}\right)\right]} \\
\text { Where } E_{A}=\text { Activation Energy } \\
T_{a b}=\text { Absolute temperature } \\
T_{r f}=\text { Reference temperature at which } H\left(T_{W}\right)=1 \text { and } T_{a b}=0
\end{gathered}
$$

$T_{W}=$ Working Temperature which is slightly above the melting temperature of PLA

So the pressure difference for zone first is

$$
\left(p_{2}-p_{1}\right)=2\left[\frac{(n+3) \bar{u}}{R^{n+1} \phi_{f}}\right]^{\frac{1}{n}}\left(z_{1}-z_{2}\right) e^{\left[E_{A}\left(\frac{1}{T_{W}-T_{a b}}+\frac{1}{T_{a b}-T_{r f}}\right)\right]}
$$

Similarly for taper section the pressure drop will be

$$
\left(p_{3}-p_{2}\right)=\frac{2 n}{3 \tan \left(\frac{\theta}{2}\right)}\left[\frac{\bar{u}}{\phi_{f}}\right]^{\frac{1}{n}}\left[\frac{1}{r_{3}^{3 / n}} \frac{1}{r_{2}^{3 / n}}\right]\left[r_{2}^{2} 2^{n+3}(n+3)\right]^{1 / n} e^{\left[E_{A}\left(\frac{1}{T_{w}-T_{a b}}+\frac{1}{T_{d b}-T_{f}}\right)\right]}
$$

The Total Pressure Drop

$$
\begin{aligned}
& \Delta p_{\text {total }}=\left(p_{2}-p_{1}\right)+\left(p_{3}-p_{2}\right) \\
& \text { The nozzle angle can be calculate by using formula } \\
& \tan \left(\frac{\theta}{2}\right)=\frac{r_{2}-r_{3}}{\Delta Z_{2}}=\frac{d_{2}-d_{3}}{\Delta Z_{2}} \quad(2 \Omega=2 \Pi N / 60, N \text { is in rpm })
\end{aligned}
$$

\section{OPERATING CONDition OF FEED Wire}

The properties of Poly-lactic acid (PLA) feed wire are mentioned in TABLE 2 below with filament operating condition. The feed wire convert it into semi liquid form as the temperature of Poly lactic acid (PLA) feed wire reach up to the glass transition temperature. The glass transition temperature generally is $0.3 \mathrm{~T}_{\mathrm{m}}$ of melting point temperature. As the feed wire temperature raised up to this temperature the wire start to melt and it convert from solid to semiliquid state and flow in nozzle according to physical law of nature these are conservation of mass, conservation of momentum, and conservation of energy.

TABLE 2: Filament Operating Conditions

\begin{tabular}{|c|l|c|c|c|}
\hline Sr. No & \multicolumn{1}{|c|}{ Property } & Symbol & Values & Unit \\
\hline 1 & Viscosity & $\mu$ & 0.000037 & Pa-s \\
\hline 2 & Temperature (at which phi and n' are calculated) & $\mathrm{T}$ & 333 & ${ }^{0} \mathrm{~K}$ \\
\hline 3 & Working Temperature $\mathrm{T}_{\mathrm{w}}$ & $\mathrm{T}_{\mathrm{w}}$ & 523 & ${ }^{0} \mathrm{~K}$ \\
\hline 4 & Absolute temperature & $\mathrm{T}_{\mathrm{abs}}$ & 300 & ${ }^{0} \mathrm{~K}$ \\
\hline
\end{tabular}


TABLE 3: Representation of the Poly-lactic Acid (PLA) Physical \& Thermal Properties.

\begin{tabular}{|c|l|c|c|}
\hline Sr. No & \multicolumn{1}{|c|}{ Property } & Values & Units \\
\hline 1 & Viscosity of PLA & $0.265-0.467$ & $\mathrm{M}$ Ps-s \\
\hline 2 & Density of PLA & 1.25 & $\mathrm{gm} / \mathrm{cm}^{3}$ at $21.5^{\circ} \mathrm{C}$ \\
\hline 3 & Thermal conductivity & 0.13 & $\mathrm{~W} / \mathrm{M}^{0} \mathrm{k}$ \\
\hline 4 & Thermal diffusivity & 0.056 & $\mathrm{~m} 2 / \mathrm{sec}$ \\
\hline 5 & Specific heat & 1800 & $\mathrm{~J} / \mathrm{Kg}{ }^{0} \mathrm{~K}$ \\
\hline 6 & Feed rate & $2.247-2.67$ & $\mathrm{~m} / \mathrm{sec}$ \\
\hline 7 & Yield Tensile Strength & 52 & $(\mathrm{MPa})$ \\
\hline 8 & \% Elongation at Yield & $10-100$ & $(\mathrm{MPa})$ \\
\hline 9 & Flexural Modulus & $345-450$ & $\left({ }^{\circ} \mathrm{C}\right)$ \\
\hline 10 & Melting Point & $120-170$ & $\left({ }^{\circ} \mathrm{C}\right)$ \\
\hline 11 & Glass Transition Temperature & $54-56$ & $\mathrm{GPa}$ \\
\hline 12 & Shear Modules & 2.4 & \\
\hline
\end{tabular}

TABLE 4: Boundary Conditions for Mathematical Model

\begin{tabular}{|c|l|c|c|}
\hline Sr. No & \multicolumn{1}{|c|}{ Boundary Condition } & Values & Units \\
\hline 1 & Inlet Velocity & 0.00000399 & $\mathrm{~m} / \mathrm{s}$ \\
\hline 2 & Inlet Temperature & 300 & ${ }^{0} \mathrm{~K}$ \\
\hline 3 & Temperature of surface (with circular and tapered section) & 523 & ${ }^{0} \mathrm{~K}$ \\
\hline 4 & Back flow temperature & 300 & ${ }^{0} \mathrm{k}$ \\
\hline 5 & Gauge Pressure at inlet and outlet & 0 & $\mathrm{~Pa}$ \\
\hline
\end{tabular}

\section{RESULT AND DISCUSSION}

TABLE 5 \& TABLE 6 represents the pressure drop analysis section wise as total pressure drop using equation no 21, 22, 23 for melt flow of feed wire across the nozzle, for various nozzle geometrical condition with same operating condition, raw material, boundary condition as mentioned in TABLE 2, TABLE 3 \& TABLE 4 above respectively. TABLE 6 represents the total pressure drop for $30^{\circ}, 60^{\circ}, 90^{\circ}$ and $120^{\circ}$ nozzle angle. The total pressure drop evaluated in TABLE 5 with respect to each nozzle angle at different exit diameter shows that the pressure drop decrease as the exit diameter of the nozzle exit diameter increases from $0.2 \mathrm{~mm}$ to $0.4 \mathrm{~mm}$. At each nozzle angle with different exit dia. $0.4 \mathrm{~mm}, 0.3 \mathrm{~mm}$ and $0.2 \mathrm{~mm}$ the numerical value of pressure drops are mentioned in below TABLE 7, TABLE 8, TABLE 9 \& TABLE 10 and its graphical representation are in Fig. 2, Fig. 3, Fig. 4, Fig. 5 and Fig. 6. The results shows that as pressure drop decreases by increasing the nozzle exit diameter from $0.2 \mathrm{~mm}$ to $0.4 \mathrm{~mm}$ and nozzle angle from 30 degree to 120 degree.

TABLE 5: Total Pressure Drop for Melt Flow Wire across Nozzle for Different Nozzle Angle and Exit Diameter

\begin{tabular}{|c|c|c|c|c|c|c|c|c|c|}
\hline $\begin{array}{c}\text { Sr. } \\
\text { No }\end{array}$ & $\begin{array}{c}\mathbf{( I n} \\
\text { Degree) } \\
\mathbf{G}\end{array}$ & $\begin{array}{c}\mathbf{D i} \\
\mathbf{( m m})\end{array}$ & $\mathbf{D}_{\mathbf{0}}(\mathbf{m m})$ & $\mathbf{Z}_{\mathbf{1}}(\mathbf{m m})$ & $\mathbf{Z}_{\mathbf{2}}(\mathbf{m m})$ & Pressure & $\begin{array}{c}\text { Pressure } \\
\text { Difference for } \\
\text { section 2 (Pa) }\end{array}$ & $\begin{array}{c}\text { Total } \\
\text { Pressure } \\
\text { Drop (Pa) }\end{array}$ & $\begin{array}{c}\text { Total } \\
\text { Pressure } \\
\mathbf{( N / m m} \mathbf{m}^{\mathbf{2}}\end{array}$ \\
\hline 1 & 30 & 3 & 0.4 & 20.148 & 4.85 & $4.94 \mathrm{E}-10$ & $5.40 \mathrm{E}-05$ & $5.40 \mathrm{E}-05$ & 53.995111 \\
\hline 2 & 30 & 3 & 0.3 & 19.967 & 5.038 & $4.90 \mathrm{E}-10$ & 0.0003201 & 0.0003201 & 320.05054 \\
\hline 3 & 30 & 3 & 0.2 & 19.77 & 5.224 & $4.84 \mathrm{E}-10$ & 0.0037366 & 0.0037366 & 3736.6336 \\
\hline 4 & 60 & 3 & 0.4 & 22.748 & 2.25 & $8.81 \mathrm{E}-10$ & $3.98 \mathrm{E}-05$ & $3.98 \mathrm{E}-05$ & 39.785437 \\
\hline 5 & 60 & 3 & 0.3 & 22.66 & 2.3382 & $8.78 \mathrm{E}-10$ & 0.0002335 & 0.0002335 & 233.46579 \\
\hline 6 & 60 & 3 & 0.2 & 22.57 & 2.424 & $8.74 \mathrm{E}-10$ & 0.0027518 & 0.0027518 & 2751.805 \\
\hline 7 & 90 & 3 & 0.4 & 23.7 & 1.3 & $1.52 \mathrm{E}-09$ & $3.94 \mathrm{E}-05$ & $3.94 \mathrm{E}-05$ & 39.378196 \\
\hline 8 & 90 & 3 & 0.3 & 23.65 & 1.35 & $1.57 \mathrm{E}-09$ & 0.0002311 & 0.0002311 & 231.05762 \\
\hline 9 & 90 & 3 & 0.2 & 23.6 & 1.4 & $1.57 \mathrm{E}-09$ & 0.002711 & 0.002711 & 2711.0452 \\
\hline 10 & 120 & 3 & 0.4 & 24.5 & 0.7505 & $1.63 \mathrm{E}-09$ & $2.36 \mathrm{E}-05$ & $2.36 \mathrm{E}-05$ & 23.625302 \\
\hline 11 & 120 & 3 & 0.3 & 24.24 & 0.779 & $1.64 \mathrm{E}-08$ & 0.0001391 & 0.0001392 & 139.16465 \\
\hline 12 & 120 & 3 & 0.2 & 24.19 & 0.808 & $1.86 \mathrm{E}-08$ & 0.0016285 & 0.0016285 & 1628.5472 \\
\hline
\end{tabular}


TABLE 6: Pressure Drop at Different Nozzle Angle

\begin{tabular}{|c|c|c|c|c|c|}
\hline $\begin{array}{c}\text { Sr. } \\
\text { No }\end{array}$ & $\begin{array}{c}\text { Exit diameter of nozzle } \\
\text { in } \mathbf{~ m m}\end{array}$ & $\begin{array}{c}\text { Nozzle angle } \\
\mathbf{a t ~ 3 0}^{\mathbf{0}}\end{array}$ & $\begin{array}{c}\text { Nozzle angle } \\
{\text { at } \mathbf{6 0}^{\mathbf{0}}}^{\mathbf{0}}\end{array}$ & $\begin{array}{c}\text { Nozzle angle } \\
\text { at 90 }^{\mathbf{0}}\end{array}$ & $\begin{array}{c}\text { Nozzle angle } \\
\text { at 120}^{\mathbf{0}}\end{array}$ \\
\hline 1 & $\begin{array}{c}\text { Pressure }\left(\mathrm{N} / \mathrm{mm}^{2}\right) \\
(\text { nozzle exit dia. } 0.4 \mathrm{~mm})\end{array}$ & 53.9951117 & 39.78543747 & 39.37819616 & 23.6253017 \\
\hline 2 & $\begin{array}{c}\text { Pressure }\left(\mathrm{N} / \mathrm{mm}^{2}\right) \\
(\text { nozzle exit dia. } 0.3 \mathrm{~mm})\end{array}$ & 320.0505449 & 233.4657888 & 231.0576205 & 139.164653 \\
\hline 3 & $\begin{array}{c}\text { Pressure }\left(\mathrm{N} / \mathrm{mm}^{2}\right)(\text { nozzle } \\
\text { exit dia. } 0.2 \mathrm{~mm})\end{array}$ & 3736.633611 & 2751.805007 & 2711.045225 & 1628.547203 \\
\hline
\end{tabular}

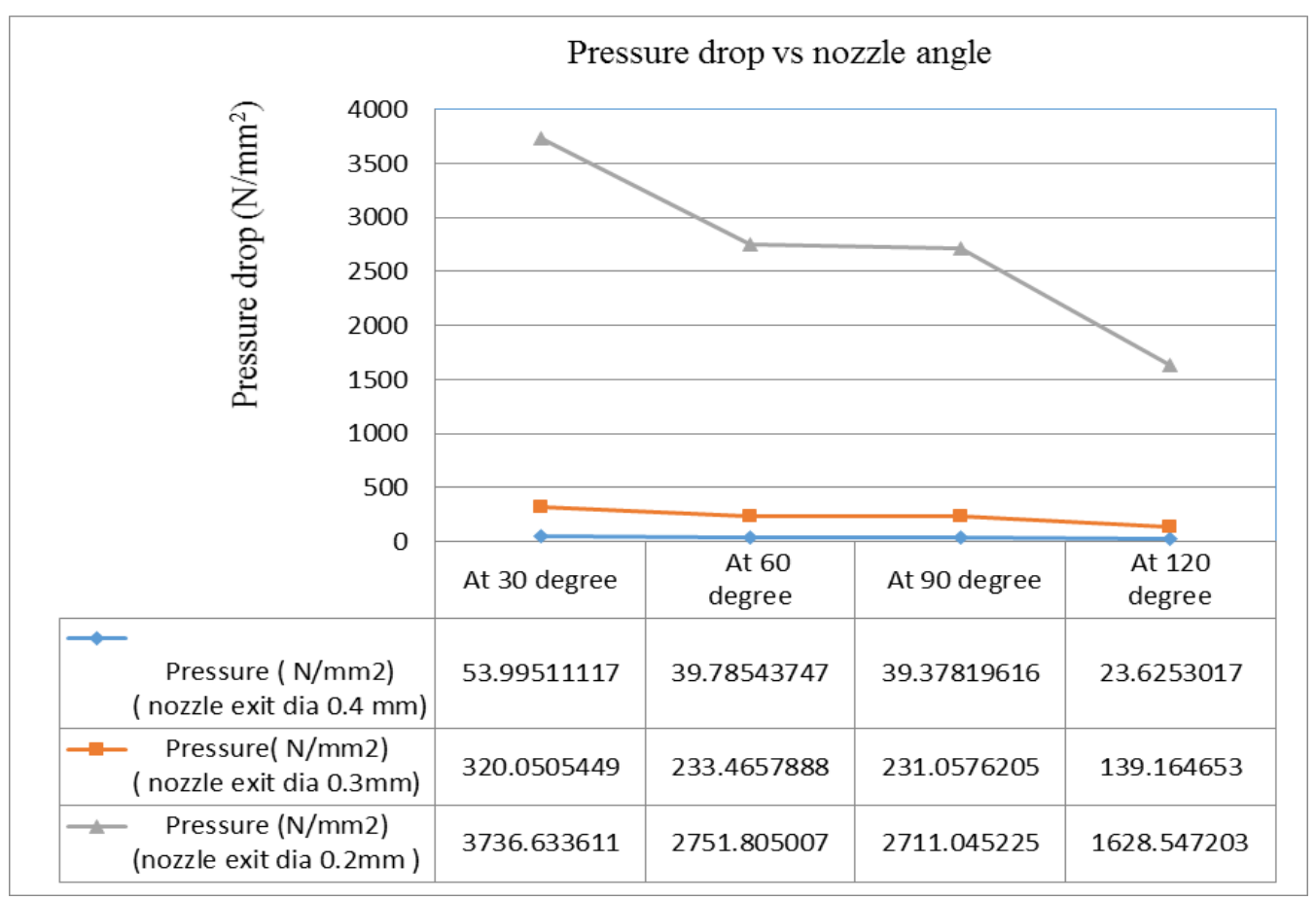

Fig. 2. Pressure drop variation over the nozzle length for exit diameter $0.2 \mathrm{~mm}, 0.3 \mathrm{~mm}$ and $0.4 \mathrm{~mm}$

The Fig. 2 represents the variation in pressure drop over the nozzle length by varying exit diameter of nozzle. In this graph the value of pressure drop at nozzle exit diameter $0.4 \mathrm{~mm}$ is $53.99 \mathrm{~N} / \mathrm{mm}^{2}$ at nozzle angle $30^{\circ}$, $39.785 \mathrm{~N} / \mathrm{mm}^{2}$ at $60^{\circ}, 39.78 \mathrm{~N} / \mathrm{mm}^{2}$ at $90^{\circ}$ and $23.625 \mathrm{~N} / \mathrm{mm}^{2}$ at 120 degree. For $0.3 \mathrm{~mm}$ exit diameter the pressure drop are $320.05 \mathrm{~N} / \mathrm{mm}^{2}$ at $30^{\circ}, 233.4657 \mathrm{~N} / \mathrm{mm}^{2}$ at $60^{\circ}$ and 231.05 at $90^{\circ}$ and $139.1646 \mathrm{~N} / \mathrm{mm}^{2}$ at $120^{0}$ respectively. Similarly for $0.2 \mathrm{~mm}$ exit dia. pressure drops are $3736.63 \mathrm{~N} / \mathrm{mm}^{2}$ at $30^{0}, 2751.80 \mathrm{~N} / \mathrm{mm}^{2}$ at 60 degree, $2711.04 \mathrm{~N} / \mathrm{mm}^{2}$ at $90^{\circ}$ and $1628.54 \mathrm{~N} / \mathrm{mm}^{2}$ at $120^{\circ}$ nozzle angle respectively. The pressure variation with respect to nozzle angle also varies in this graph, the pressure changes with the nozzle angle $30^{\circ}$ to $120^{\circ}$ and with each exit diameter. The value of pressure drop is maximum at $0.2 \mathrm{~mm}$ exit dia. with 30 degree nozzle angle and minimum at $0.4 \mathrm{~mm}$ dia. with $120^{\circ}$ nozzle angle. Highest pressure drop at exit gives minimum layer thickness, less material consumption rate, fine resolution, accuracy and good strength in part but to feed the wire in to nozzle high torque is required and situation of nozzle jamming arises and repeat constantly. So to rectify nozzle jamming problem exit diameter of nozzle or nozzle angle have to increase. Here to achieve the best possible resolution, accuracy, strength and other required parameter the optimum parameter of nozzle angle is $120^{\circ}$ with because $0.2 \mathrm{~mm}$ exit diameter $120^{\circ}$ reduce feed force and $0.2 \mathrm{~mm}$ exit diameter gives best resolution. Graph shows the pressure variation over the nozzle length by varying nozzle angle from $30^{\circ}$ to $120^{\circ}$ and exit diameter from $0.4 \mathrm{~mm}$ to $0.2 \mathrm{~mm}$.

TABLE 7: Pressure Drop at $30^{\circ}$ for Feed Wire.

\begin{tabular}{|c|c|c|}
\hline \multirow[t]{2}{*}{ Sr. No } & \multicolumn{2}{|c|}{ Pressure drop at nozzle angle $30^{\circ}$} \\
\hline & Exit diameter of nozzle (mm) & Pressure $\left(\mathrm{N} / \mathrm{mm}^{2}\right)$ \\
\hline 1 & 0.2 & 3736.6336 \\
\hline 2 & 0.3 & 320.05054 \\
\hline 3 & 0.4 & 53.995111 \\
\hline
\end{tabular}




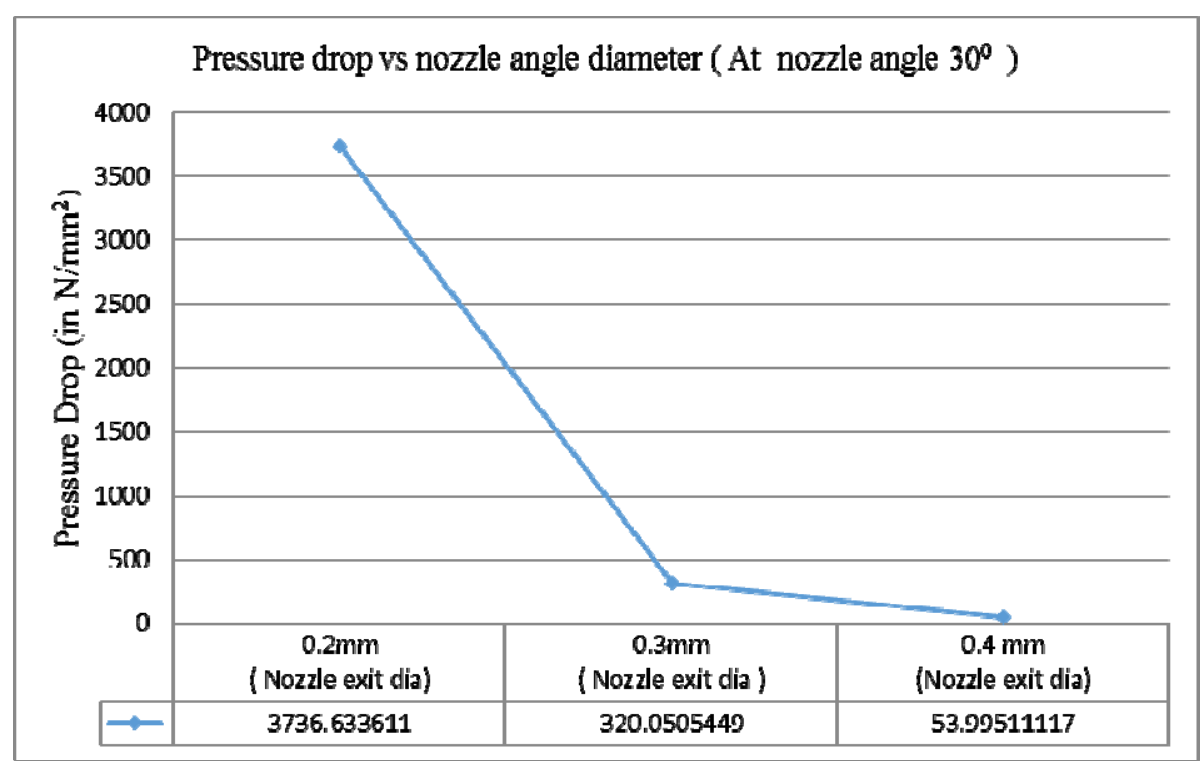

Fig. 3. Pressure drop variation over the nozzle length for nozzle angle $30^{\circ}$

The Fig. 3 represents the pressure drop values from inlet to outlet at constant nozzle angle of 30 degree by varying exit dia. from $0.2 \mathrm{~mm}$ to $0.4 \mathrm{~mm}$.

TABLE 8: Pressure Drop at $60^{\circ}$ for Feed Wire

\begin{tabular}{|c|c|c|}
\hline \multirow[t]{2}{*}{$\mathbf{Z Z}$} & \multicolumn{2}{|c|}{ Pressure drop at nozzle angle $60^{\circ}$} \\
\hline & Exit diameter of nozzle (mm) & Pressure $\left(\mathrm{N} / \mathbf{m m}^{2}\right)$ \\
\hline 1 & 0.2 & 2751.805 \\
\hline 2 & 0.3 & 233.46579 \\
\hline 3 & 0.4 & 39.785437 \\
\hline
\end{tabular}

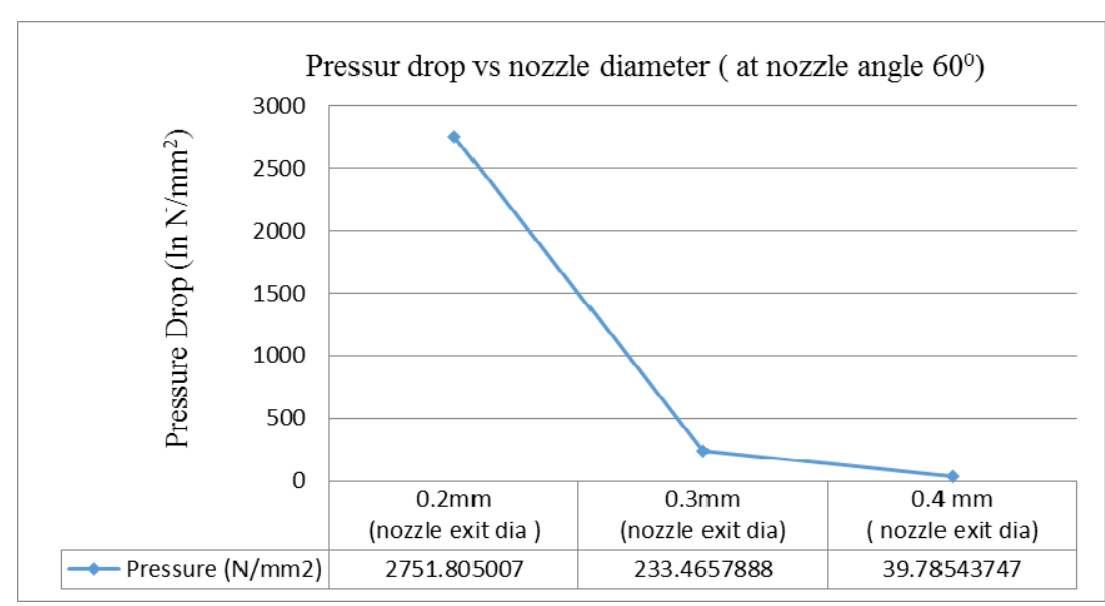

Fig. 4. Pressure drop variation over the nozzle length for nozzle angle $60^{\circ}$

The Fig. 4 represents the pressure drop values decreases from inlet to outlet at constant nozzle angle of 60 degree by varying exit diameter from $0.2 \mathrm{~mm}$ to $0.4 \mathrm{~mm}$.

TABLE 9: Pressure Drop at $90^{\circ}$ for Feed Wire

\begin{tabular}{|c|c|c|}
\hline \multirow[t]{2}{*}{ Sr. No } & \multicolumn{2}{|c|}{ Pressure drop at nozzle angle $90^{\circ}$} \\
\hline & Exit diameter of nozzle (mm) & Pressure $\left(\mathrm{N} / \mathrm{mm}^{2}\right)$ \\
\hline 1 & 0.2 & 1628.547203 \\
\hline 2 & 0.3 & 139.164653 \\
\hline 3 & 0.4 & 23.6253017 \\
\hline
\end{tabular}




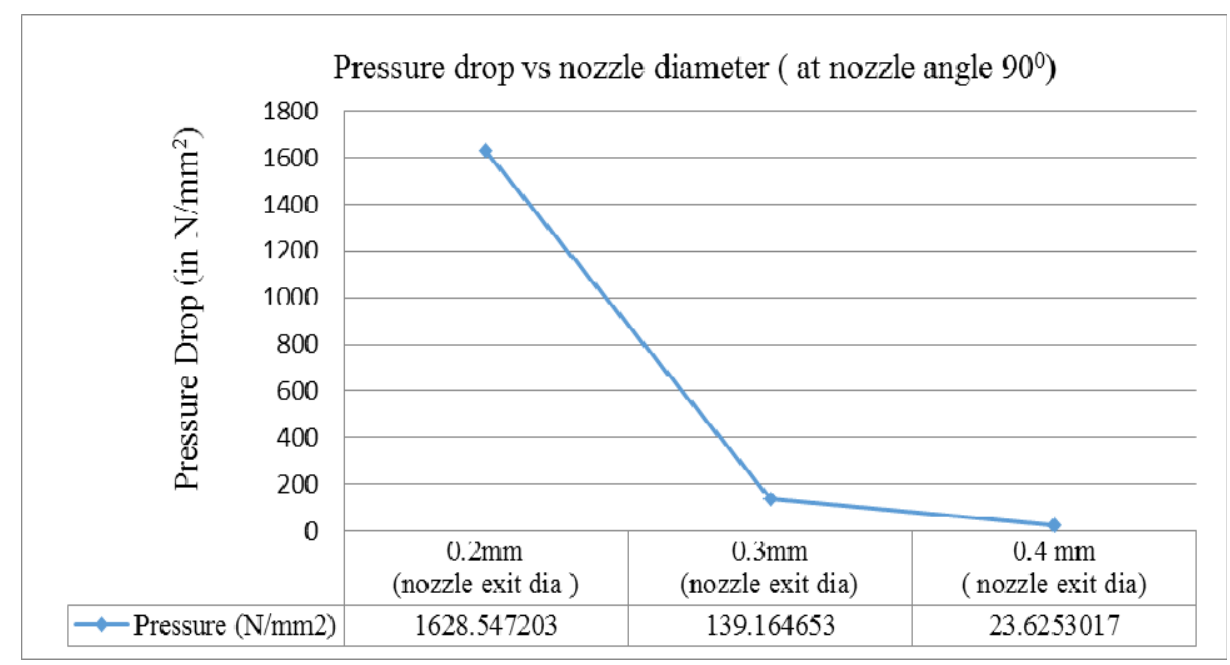

Fig. 5. Pressure drop variation over the nozzle length for nozzle angle $90^{\circ}$

The Fig. 5 represents the pressure drop values varies $1628.54 \mathrm{~N} / \mathrm{mm}^{2}$ to $23.65 \mathrm{~N} / \mathrm{mm}^{2}$ from inlet to outlet at nozzle angle of $90^{\circ}$ by varying exit diameter from $0.2 \mathrm{~mm}$ to $0.4 \mathrm{~mm}$.

TABLE 10: Pressure Drop Analysis at $120^{\circ}$ for Feed Wire

\begin{tabular}{|c|c|c|}
\hline \multirow[t]{2}{*}{ Sr. No } & \multicolumn{2}{|c|}{ Pressure drop at nozzle angle $120^{\circ}$} \\
\hline & Exit diameter of nozzle $(\mathrm{mm})$ & Pressure $\left(\mathrm{N} / \mathrm{mm}^{2}\right)$ \\
\hline 1 & 0.2 & 313.7335473 \\
\hline 2 & 0.3 & 26.80669419 \\
\hline 3 & 0.4 & 4.551065038 \\
\hline
\end{tabular}

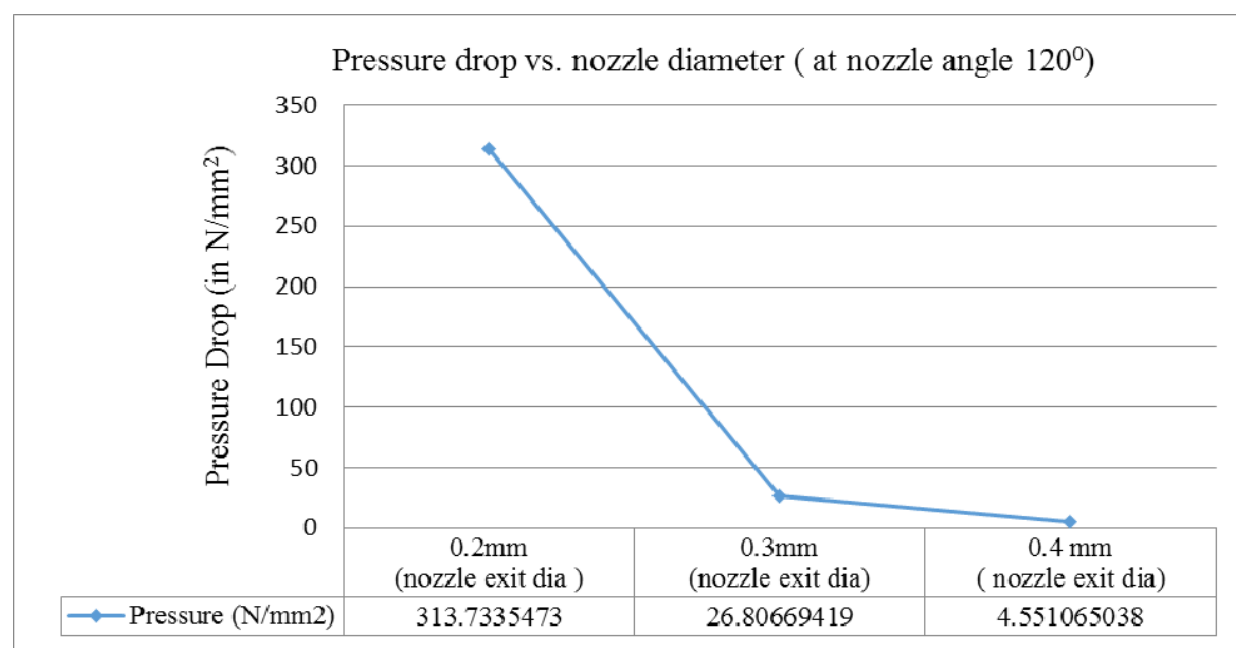

Fig. 6. Pressure drop variation over the nozzle length for nozzle angle $120^{\circ}$

The Fig. 6 represents the pressure drop values from $313.73 \mathrm{~N} / \mathrm{mm}^{2}$ to $4.55 \mathrm{~N} / \mathrm{mm}^{2}$ from inlet to outlet at constant nozzle angle of $120^{\circ}$ by varying exit diameter from $0.2 \mathrm{~mm}$ to $0.4 \mathrm{~mm}$. Pressure drop has significant role in controlling the layer thickness, resolution, material consumption, gaps between the adjacent layer and also control the feed force which is required to feed the wire in to nozzle. Here every graph shows the same trends of pressure drop by varying nozzle exit diameter as well as nozzle angle. To optimize the all above parameter the results recommend nozzle angle should be $120^{\circ}$ with intermediate diameter $0.3 \mathrm{~mm}$ for to achieve the best output result. 


\section{CONCLUSION}

The pressure drop analysis across the nozzle is done by using mathematical modelling of poly-lactic acid (PLA) feed wire. The results of mathematical analysis shows that as the nozzle angle increases from $30^{\circ}, 60^{\circ}$, $90^{\circ}$ and $120^{\circ}$ with combination of $0.2 \mathrm{~mm}, 0.3 \mathrm{~mm}$, and $0.4 \mathrm{~mm}$ exit diameter, the pressure drop decreases with nozzle exit diameter from $0.2 \mathrm{~mm}, 0.3 \mathrm{~mm}$ and $0.4 \mathrm{~mm}$. The best possible combination of nozzle angle and exit diameter are achieved for thin extruded wire without any irregular flow of melt flow behaviour. For $3 \mathrm{~mm}$ feed wire the best possible combination of exit diameter and nozzle angle is $0.2 \mathrm{~mm}$ with $120^{\circ}$. The pressure drop and quality of filament depends on nozzle geometrical parameter like nozzle angle and exit diameter. The results obtained by applying mathematical modelling can be verified by computational analysis.

\section{REFERENCES}

[1] Gebhardt, A. (2003). Rapid prototyping, p.47, Hanser: Munich.

[2] Gibson, I., Rosen, D., \& Stucker, B. (2014). Additive manufacturing technologies 3D printing, rapid prototyping, and direct digital manufacturing. Springer.

[3] Kumar, L., Tanveer, Q., Kumar, V., Javaid, M., \& Haleem, A. (2016). Developing low cost 3 D printer. Int. Journal of Applied Sciences and Engineering Research, 5(6), 433-447.

[4] Utela, B., Storti, D., Anderson, R., \& Ganter, M. (2008). A review of process development steps for new material systems in three dimensional printing (3DP). Journal of Manufacturing Processes, 10(2), 96-104.

[5] Cerardi, A., Caneri, M., Meneghello, R., Concheri, G., \& Ricotta, M. (2013). Mechanical characterization of polyamide cellular structures fabricated using selective laser sintering technologies. Materials \& Design, 46, 910-915.

[6] Hussein, A., Hao, L., Yan, C., Everson, R., \& Young, P. (2013). Advanced lattice support structures for metal additive manufacturing. Journal of Materials Processing Technology, 213(7), 1019-1026.

[7] Islam, M. N., Boswell, B., \& Pramanik, A. (2013). An investigation of dimensional accuracy of parts produced by three-dimensional printing. In Proc of the world congress on engineering V.1, 3-5.

[8] Jackson, T. R., Liu, H., Patrikalakis, N. M., Sachs, E. M., \& Cima, M. J. (1999). Modeling and designing functionally graded material components for fabrication with local composition control. Materials \& Design, 20(2), 63-75.

[9] Lee, C. S., Kim, S. G., Kim, H. J., \& Ahn, S. H. (2007). Measurement of anisotropic compressive strength of rapid prototyping parts. Journal of materials processing technology, 187, 627-630.

[10] Sugavaneswaran, M., \& Arumaikkannu, G. (2014). Modelling for randomly oriented multi material additive manufacturing component and its fabrication. Materials \& Design, 54, 779-785.

[11] Nimawat, D., \& Meghvanshi, M. (2012). Using Rapid Prototyping Technology in mechanical Scale Models. Int. J. of Engineering Research and Application, 2(2), 215-219.

[12] Ollison, T., \& Berisso, K. (2010). Three-dimensional printing build variables that impact cylindricity. J. Ind. Tech, 26(1), 2-10.

[13] Pham, D. T., Dimov, S. S., Ji, C., \& Gault, R. S. (2003). Layer manufacturing processes: technology advances and research challenges.

[14] Rimašauskas, M., \& Balevičius, G. (2013). The Influence of Water Absorption to the Properties of Photopolymer used in PolyJet.

[15] Laeng, J., Stewart, J. G., \& Liou, F. W. (2000). Laser metal forming processes for rapid prototyping-A review. Int. J. of Production Research, 38(16), 3973-3996.

[16] Machover, C. (1996). The Cad/Cam Handbook. McGraw-Hill

[17] Bhanu, B. (1987). CAD-based robot vision. Computer, 20(8), 13-16.

[18] Vijay, P., Danaiah, P., \& Rajesh, K. V. D. (2011). Critical parameters effecting the rapid prototyping surface finish. Journal of Mechanical Engineering and Automation, 1(1), 17-20.

[19] Pandey, P. M. (2010). Rapid prototyping technologies, applications and part deposition planning. Retrieved October, 15.

[20] Mellor, S., Hao, L., \& Zhang, D. (2014). Additive manufacturing: A framework for implementation. International Journal of Production Economics, 149, 194-201.

[21] Pham, D. T., \& Gault, R. S. (1998). A comparison of rapid prototyping technologies. Int. J. of machine tools and manufacture, 38(10), $1257-1287$

[22] Oudjene, M., Penazzi, L., \& Batoz, J. L. (2007). Towards the three-dimensional FE analysis of rapid prototyping tools for sheet metal stamping process. Finite elements in analysis and design, 43(8), 611-619.

[23] Šimunić, N., Mustapić, N., \& Bursać, D. (2013, January). Ergonomic design of handle using rapid prototyping technology. In 5th International Ergonomics Conference.

[24] Prakash, W. N., Sridhar, V. G., \& Annamalai, K. (2014). New product development by DFMA and rapid prototyping. ARPN J Eng Appl Sci, 9(3), 274-279.

[25] Javaid, M., Kumar, L., Haleem, A., \& Kumar, V. (2015). Product Design and Development using Polyjet Rapid Prototyping Technology. Control Theory and Informatics, 5(3), 12-20.

[26] Wong, K. V., \& Hernandez, A. (2012). A review of additive manufacturing. ISRN Mechanical Engineering, 2012.

[27] Choi, S. H., \& Samavedam, S. (2002). Modelling and optimisation of rapid prototyping. Computers in industry, 47(1), 39-53.

[28] Kumar, V., Kumar, L., \& Haleem, A. (2016). Rapid prototyping technology ranking using an ANP approach and its sensitivity analysis. International Journal of Engineering Sciences \& Research Technology, 5(9), 93-103.

[29] Haleem, A., Kumar, V., Kumar, L. (2017). Computational Analysis of Polylactic Acid (PLA) Feed Wire in Fused Deposition Modeling Machine. Int J Recent Sci Res. 8(6), pp. 17971-17976.

[30] Kumar, V., Kumar, L., \& Haleem, A. (2016). Selection of Rapid Prototyping Technology Using an ANP Based Approach. IOSR Journal of Mechanical and Civil Engineering (IOSR-JMCE), 13(4), 71-78.

[31] Kumar, L., Haleem, A., Tanveer, Q., Javaid, M., Shuaib, M., \& Kumar, V. (2017). Rapid Manufacturing: Classification and Recent Development. International Journal of Advanced Engineering Research and Science, 4(3), 29-40.

[32] Xiao, L., Wang, B., Yang, G., \& Gauthier, M. (2012). Poly (lactic acid)-based biomaterials: synthesis, modification and applications.

[33] Garlotta, D. (2001). A literature review of poly (lactic acid). Journal of Polymers and the Environment, 9(2), 63-84.

[34] Wittbrodt, B., \& Pearce, J. M. (2015). The effects of PLA color on material properties of 3-D printed components. Additive Manufacturing, 8, 110-116.

[35] Hamad, K., Kaseem, M., \& Deri, F. (2011). Melt rheology of poly (lactic acid)/low density polyethylene polymer blends. Advances in Chemical Engineering and Science, 1(04), 208.

[36] Gajdoš, I., \& Slota, J. (2013). Influence of printing conditions on structure in FDM prototypes. Technical Gazette, 20(2), 231-236.

[37] Qiu, X. J., Zheng, W. H., Tang, Y. T., \& Lu, F. (2015). The Test Verification Design Method Based on Rapid Prototyping Technology of Aero-engine. Procedia Engineering, 99, 981-990. 
[38] Kumar, V., Kumar, L., Haleem, A., \& Rajesh. (2016). Design and Development of Thermal Rapid Prototyping Machine and Its Application. International Journal of Emerging Technologies in Engineering Research, 4(2), 101-106.

[39] Bergman, T. L., \& Incropera, F. P. (2011). Introduction to heat transfer. John Wiley \& Sons.

[40] Bourell, D. L., Beaman, J. J., Leu, M. C., \& Rosen, D. W. (2009). A brief history of additive manufacturing and the 2009 roadmap for additive manufacturing: looking back and looking ahead.

[41] Mohamed, O. A., Masood, S. H., \& Bhowmik, J. L. (2015). Optimization of fused deposition modeling process parameters: a review of current research and future prospects. Advances in Manufacturing, 3(1), 42-53.

[42] Mireles, J., Espalin, D., Roberson, D., Zinniel, B., Medina, F., \& Wicker, R. (2012, August). Fused deposition modeling of metals. In International SFF symposium held in Austin, Texas (pp. 6-8).

[43] Zhou, J. G., Kokkengada, M., He, Z., Kim, Y. S., \& Tseng, A. A. (2004). Low temperature polymer infiltration for rapid tooling. Materials \& design, 25(2), 145-154.

[44] Patel, V. N., \& Kadia, M. K. P. (2015). Parametric Optimization of the process of Fused Deposition Modeling in Rapid Prototyping Technology-A Review. International Journal for Innovative Research in Science and Technology, 1(7), 80-82.

[45] Liang, M., Ng, W. R., Chang, K., Gbele, K., Gehm, M. E., \& Xin, H. (2014). A 3-D Luneburg lens antenna fabricated by polymer jetting rapid prototyping. IEEE Transactions on Antennas and Propagation, 62(4), 1799-1807.

[46] Onuh, S. O., \& Yusuf, Y. Y. (1999). Rapid prototyping technology: applications and benefits for rapid product development.

[47] Kumar, L., Kumar, V., \& Haleem, A. (2016). Rapid Prototyping Technology for New Product Development. International Journal of Innovative Science, Engineering \& Technology, 3(1), 287-292.

[48] Sood, A. K., Ohdar, R. K., \& Mahapatra, S. S. (2009). Improving dimensional accuracy of fused deposition modelling

[49] Agrawal, A. (2014). Computational and mathematical analysis of dynamics of fused deposition modelling based rapid prototyping technique for scaffold fabrication (Doctoral dissertation, National Institute of Technology Rourkela).

\section{AUTHOR PROFILE}

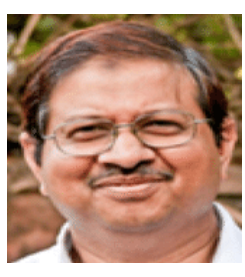

Dr. Abid Haleem is Professor of Mechanical Engineering in Jamia Millia Islamia, New Delhi, India. Has published more than 160 research papers in good international and national journals such as Resources Policy, Benchmarking: An International Journal, Production Planning and Control, International Journal of Logistic Systems and Management, Journal of Enterprise Information Management, Journal of Cleaner Production, International Journal of Business Excellence, Global Journal of Flexible Systems Management, Renewable and Sustainable Energy, Energy Review, etc. Has more than 28 years of teaching, consulting and research experience in varied areas such as Systems Management, Technology Management, Supply Chain Management and allied areas of Industrial Engineering.

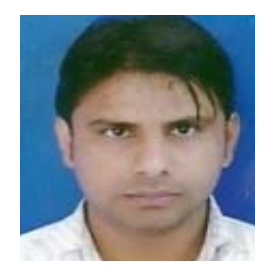

Mr Vineet Kumar completed his B. Tech in Mechanical Engineering from G.L.A.I.T.M Mathura, Uttar Pradesh Technical University, Lucknow, India. Then he has completed his M. Tech in Production Engineering from MNNIT Allahabad, Uttar Pradesh, India. He is now pursing his Ph. D from Jamia Millia Islamia, New Delhi, India in Rapid Prototyping. He has Eight year teaching experience and published more than ten papers in international and national conferences.

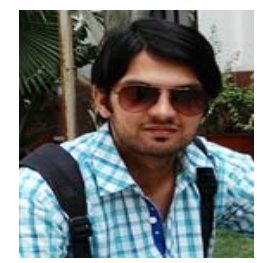

Mr. Lalit Kumar is pursuing his Ph. D in 'Product development through Rapid Prototyping Technique' from Department of Mechanical Engineering in Jamia Millia Islamia, New Delhi, India. He is currently working as an Assistant Professor with the Discipline of Mechanical Engineering at Inderprastha Engineering College, Ghaziabad. He has done his $\mathrm{M}$. Tech in manufacturing and automation from Y.M.C.A UST Faridabad. His research interests are: Rapid prototyping, Product Development, Green manufacturing etc. He has five years of teaching and research experience, and published more than 15 research papers in international and national journals and conferences. 